\title{
Sudden and rapid decline of the abundant marsupial Bettongia penicillata in Australia
}

\author{
Adrian F. Wayne, Marika A. Maxwell, Colin G. Ward, Chris V. Vellios \\ Ian Wilson, Julia C. Wayne and Matthen R. Williams
}

\begin{abstract}
The woylie Bettongia penicillata is categorized as Critically Endangered, having declined by c. $90 \%$ between 1999 and 2006. The decline continues and the cause is not fully understood. Within a decline diagnosis framework we characterized the nature of the decline and identified potential causes, with a focus on the species' largest populations, located in south-west Western Australia. We described the spatio-temporal pattern of the decline, and several attributes that are common across sites. We categorized the potential causes of the decline as resources, predators, disease and direct human interference. Based on the available evidence the leading hypothesis is that disease may be making woylies more vulnerable to predation but this remains to be tested. No substantial recoveries have been sustained to date, and one of the three remaining indigenous populations now appears to be extinct. Therefore, verifying the factors causing the decline and those limiting recovery is becoming increasingly urgent. Active adaptive management can be used to test putative agents, such as introduced predators. Insurance populations and ecological monitoring should also be included in an integrated conservation and management strategy for the species.
\end{abstract}

Keywords Declining population paradigm, population decline, predator, threatened species, wildlife disease

\section{Introduction}

The woylie Bettongia penicillata is an important 1 mycophageous ecosystem engineer and propagule vector (particularly of mycorrhizal fungi), previously found across much of southern and central Australia (Christensen, 1980; Garkaklis et al., 2004; Zosky, 2012; Wayne et al., 2013). By the 1960 s the species was found only in three small areas in south-west Western Australia but it then made a significant recovery. In 1996 it became the first Australian taxon to be removed from threatened species lists as a result of successful conservation actions, principally fox

Adrian F. WAYNe (Corresponding author), Marika A. MAXWEll, Colin G. Ward, Chris V. Vellios, Ian Wilson, Julia C. Wayne, and Matthew R. WiLliams Department of Parks and Wildlife, Locked Bag 2, Manjimup, WA 6258, Australia. E-mail adrian.wayne@dpaw.wa.gov.au

Received 18 October 2012. Revision requested 7 January 2013.

Accepted 5 April 2013. First published online 29 November 2013. control and translocations (Start et al., 1995). However, since 1999 populations throughout south-west Western Australia have undergone unexpected, rapid and substantial declines. By 2006 this keystone species had declined by c. 90\% (c. 182,000 individuals). It is now considered one of the most threatened marsupials in Australia and is categorized as Critically Endangered on the IUCN Red List (Wayne et al., 2008a, 2013). The decline continues and the causes are not proven.

The decline diagnosis framework we applied to the woylie (Wayne et al., 2013) is based on the declining population paradigm and cognate scientific approaches (Caughley, 1994; Caughley \& Gunn, 1996; Peery et al., 2004). Having verified that the decline is real and reviewed the ecology of the species (Wayne et al., 2013), we focus on (1) determining the spatial, temporal and demographic characteristics of the observed decline, (2) identifying all potential causes, and (3) using available evidence to shortlist potential causes. This research provides the basis for future work to rigorously test putative causes and, given the evidence, determine the most appropriate conservation and management responses.

\section{Study area}

The study area (Fig. 1) is the Upper Warren region of southwest Western Australia, which includes 140,000 ha of publicly managed forest. Perup Nature Reserve constitutes the eastern part of the region, and the western portion, broadly known as Greater Kingston, consists of National Park and State Forest (DEC, 2012). The Perup/Kingston subdivision is consistent with woylie genetic distinctions (Pacioni et al., 2011). The largely contiguous public forests are subdivided into management units of c. 5,00o ha, called forest blocks.

The Mediterranean type climate supports forests dominated by jarrah Eucalyptus marginata, marri Corymbia calophylla and wandoo Eucalyptus wandoo. Management activities in the region (Wayne et al., 2006, 2013; DEC, 2012) have included fire (McCaw et al., 2005), timber harvesting (Wayne et al., 2006 \& references therein) and the control of the introduced red fox Vulpes vulpes using fox baits since 1977; since late 1996 fox baits have been distributed quarterly on a broad scale, primarily by aircraft (Burrows \& Christensen, 2002, Wayne et al., 2006). 


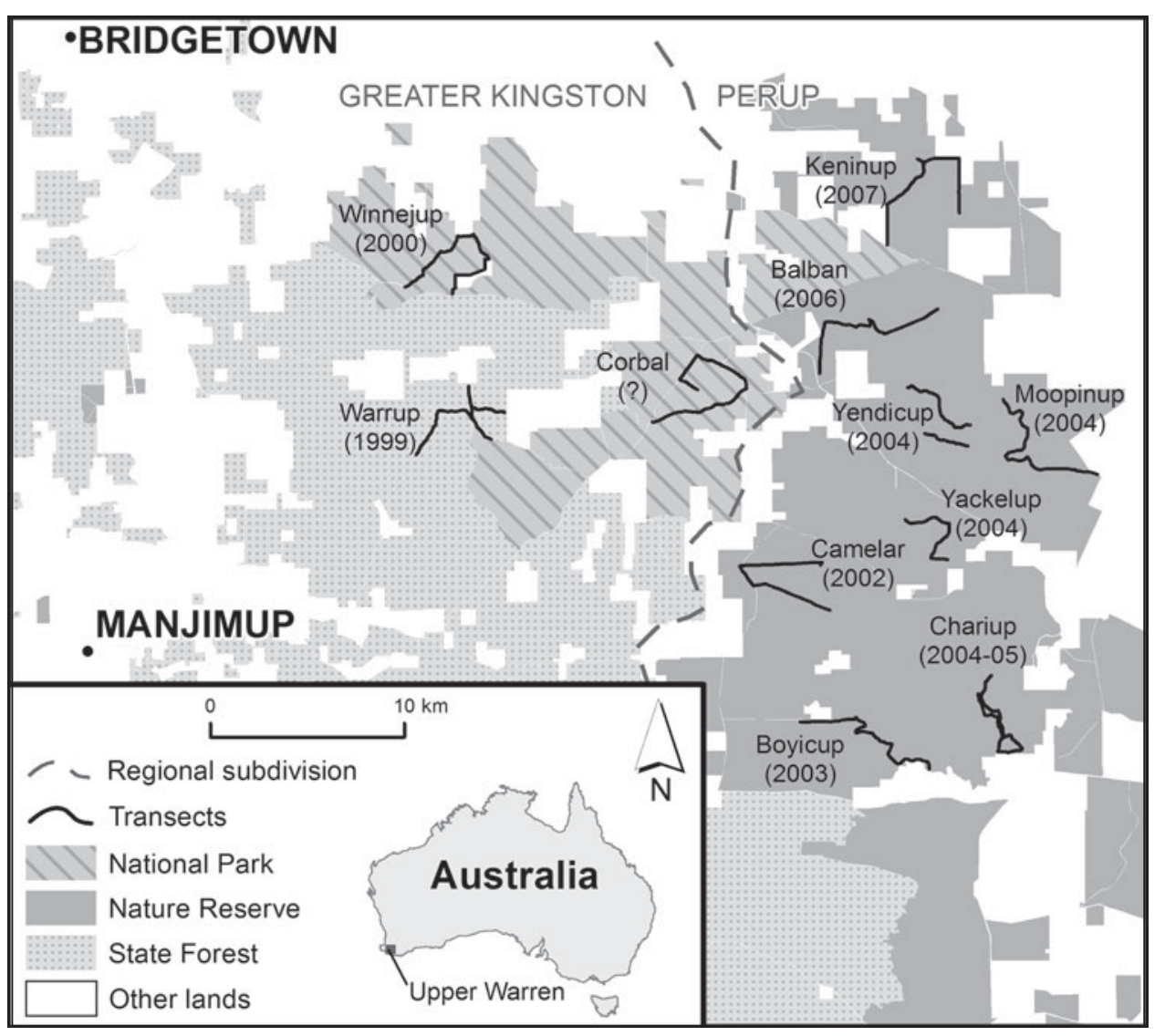

FIG. 1 Woylie monitoring sites in the Upper Warren region, south-west Australia, and the year in which recent substantial declines began. The dashed line distinguishes the Greater Kingston area (west) from the Perup area (east). The inset shows the location of the main map in Australia.

\section{Methods}

\section{Data collation and establishment of monitoring transects}

We aggregated $>35$ historical independent trapping datasets (1974 to present) from the Upper Warren into a single database, with $>62,000$ animal records, including $>28,000$ woylie capture records involving $>5,500$ individuals (DEC, 2008; Wayne et al., 2013).

Monitoring transects across the Upper Warren region were standardized in 2005 (Fig. 1), with each transect involving 50 wire-cage traps $(20 \times 20 \times 45 \mathrm{~cm})$ baited with peanut butter, rolled oats and sardines. The traps were spaced $200 \mathrm{~m}$ apart, adjacent to minor forest tracks, and each one operated for 4 consecutive nights. Captured individuals were uniquely marked with ear tags for identification, and standardized data and sample collection methods were used. Non-standard variants of this trapping methodology were used on some pre-existing transects (Balban, Yackelup and Yendicup; Wayne et al., 2013) to enable longitudinal comparisons within these sites to continue.

Surveys along transects were conducted each spring (October-November) and autumn (March-April) during 2005-2007. Thereafter surveys were conducted annually on eight transects (consistently either in spring or autumn, depending on the transect), biannually on two transects (Keninup and Warrup) and periodically at Corbal (Wayne et al., 2013). Monitoring was conducted in accordance with requisite procedures, protocols and approvals (Wayne et al., 2013).

Woylie capture rates in the Upper Warren are highly correlated with abundance estimations based on capturemark-recapture modelling across time and space and across the observed range of woylie densities (Wayne et al., 2013) and so were used in this study as an index of abundance. On some occasions between 2000 and 2010 a non-standard bait was used at the Balban trapping transect, to reduce woylie captures and increase capture rates of other native species (Wayne et al. 2008b). Capture rates using the alternative meat-based 'smelly' bait were adjusted to an equivalent capture rate using standard bait (peanut, oats and sardines); i.e. $y=0.0+3.6 \times \log (x+1)$, where $\mathrm{x}=$ woylie capture rate (\%) using smelly bait and $\mathrm{y}=$ woylie capture rate (\%) using standard bait. The regression model used to derive this relationship was based on a comparison of capture rates using the two bait types on the same sites (Balban, Winnejup and Warrup, 1997-2008) within a month of each other $\left(R^{2}=0.98\right.$, $\mathrm{P}<0.001, \mathrm{n}=10$ ). In this way the Balban data could be reliably included to calculate regional-scale annual median capture rates and assess spatial patterns of decline. 
The main variations in survey methodology along the transects in the Upper Warren prior to 2005 were summarized by Wayne et al. (2013) and generally related to differences such as the time of year and frequency of trapping, number of traps per transect and, in particular, the level of detail collected on captured individuals (e.g. identification, biometrics). The effect of such variations over space and time on capture rates is unknown but may be considered minor with respect to the overall population trends examined here.

The timing of the commencement of decline at monitoring sites was generally based on trapping data (i.e. $>10 \%$ decline in capture rate within a given year). At Warrup and Winnejup, where trapping data were absent or insufficient in some years, detection rates from routine spotlight data were also used (Wayne et al., 2005, 2013 \& unpubl. data).

\section{Demographic attributes}

A conservative selection of datasets were used to investigate woylie demographics, to provide robust and reliable results. Demographic data prior to 1998 were considered inadequate for a regional assessment. A subset of six sites (Keninup, Warrup, Camelar, Boyicup, Moopinup and Chariup) was used because the survey methodology was comparable over space and time (Wayne et al., 2013) and these sites had the most comprehensive and reliable datasets. Nonetheless, within this subset there was still some variation between the datasets for each attribute investigated (Table 1); for example there were no data for Chariup in 2002, 2004 or 2009, and the number of breeding females was based on data from Keninup, Warrup and Camelar only.

The annual mean for each of the demographic attributes was derived per site from the means for each session within a given year (i.e. equal statistical weight was assigned to each session within a year). Annual measures across the region were derived from the mean across sites within a given year (i.e. equal statistical weight was assigned to each site).

Subadults were defined as independent and sexually immature. Adulthood was based on sexual maturity or, in some cases, other indicators that individuals were mature albeit not breeding (e.g. age based on trap history and/or body mass).

Females were considered breeding if a pouch young was present (97\% of cases identified as breeding) or the pouch was active but without pouch young (e.g. lactating teat). Repeat measures of the same individual from different trapping sessions within a given year were considered independent and were included in annual figures, given that the sampling intervals (generally $>120$ days) were sufficient relative to the 100-day breeding cycle (Christensen, 1980, 1995).

\section{Results}

\section{Characteristics of the decline}

Individual monitoring transects in the Upper Warren showed increases in woylie numbers between the 1970 s and 2007 (Figs 2-4). Commonly there were marked increases in woylie capture rates between the first and second years of a transect survey (e.g. Boyicup, Chariup and Moopinup, 1998-1999; Balban, 2000-2001; and Keninup, 2005-2006), which are attributed to a preliminary phase of trap-learning by woylies (A. Wayne, unpubl. data). There were also marked increases in the capture rates of woylies associated with improvements to the fox-baiting regime (e.g. Boyicup, 1979-1980; Yendicup, 1989-1990; Warrup and Winnejup, 1994-1998; and more generally since 1996). The first detectable declines on individual transects varied between 1999 (Warrup, Greater Kingston) and 2007 (Keninup, northern Perup; Figs 1-4). The first apparent recovery began at Warrup in 2005 but, having recovered to a $40 \%$ capture rate, the population began to decline again in 2009 (Fig. 2).

The characteristics of the decline were similar across sites throughout the Upper Warren. Prior to the decline all sites had a capture rate of $40-80 \%(>1.0$ woylies per ha; mean $=61 \%$ or 1.5 woylies per ha; based on the relationship between capture rates $(x)$ and density estimates $(y)$ modelled by Wayne et al., 2013); $R^{2}=0.90, \mathrm{P}<0.0001$, $\mathrm{n}=16$, with $y=0.000+2.519 x)$. The decline occurred at each site for a mean of 4 years (range 3-5 years), with $25-95 \%$ annual rates of decline. The profile of the annual rate of decline over time was similar across sites (Fig. 5), with an overall mean reduction of $96 \%$ (range $87-100 \%$ ). A spatial pattern was evident in the decline in Perup: beginning in Camelar in 2002, the decline extended by c. $4 \mathrm{~km}$ per year and ended $22 \mathrm{~km}$ north, in Keninup, in 2007 (Fig. 6).

\section{Demographic attributes}

There were insufficient data to investigate age ratio (subadults : adults) over time, given that only $1.6 \%$ of the 3,443 independent woylie captures across the six sites examined during 1998-2010 were subadults. Datasets considered sufficiently large and reliable were used to examine sex ratio, proportion of adult females breeding and body mass (Table 1 ).

There was no apparent pattern in adult sex ratio or proportion of adult females breeding when examined by year (1998-2010), but adult body mass steadily increased by $15 \%$, from an annual regional mean of $1,293 \pm$ SE $34 \mathrm{~g}$ in 1998 to $1,491 \pm$ SE $14 \mathrm{~g}$ in 2010 (with a peak of $1,535 \pm$ SE $54 \mathrm{~g}$ in 2007). Associations were more pronounced when regional 
TABLE 1 Summary of the number of adults at six study sites, used to investigate demographic attributes over time. The attributes investigated were the age and sex ratios, the $\%$ of females breeding, and the mean adult body mass. Blank cells indicate that no surveys were conducted; o indicates that surveys were conducted but no data are available.

\begin{tabular}{|c|c|c|c|c|c|c|c|}
\hline Year & Keninup & Boyicup & Moopinup & Chariup & Warrup & Camelar & Total \\
\hline \multicolumn{8}{|c|}{ Number of adults used to derive age and sex ratios } \\
\hline 1998 & & 55 & 43 & & & & 98 \\
\hline 1999 & & 125 & 85 & 99 & & & 309 \\
\hline 2000 & & 108 & 97 & 90 & & 66 & 361 \\
\hline 2001 & & 109 & 89 & 100 & 15 & 63 & 376 \\
\hline 2002 & & 107 & 101 & & 15 & 30 & 253 \\
\hline 2003 & & 54 & 89 & 101 & 16 & 22 & 282 \\
\hline 2004 & & 33 & 61 & & 13 & 12 & 119 \\
\hline 2005 & 47 & 11 & 8 & 56 & 60 & 1 & 183 \\
\hline 2006 & 131 & 7 & 3 & 10 & 62 & 0 & 213 \\
\hline 2007 & 139 & 3 & 6 & 7 & 71 & 1 & 227 \\
\hline 2008 & 121 & 5 & 6 & & 75 & 2 & 209 \\
\hline 2009 & 46 & 8 & 3 & 2 & 64 & 7 & 130 \\
\hline 2010 & 27 & 17 & 2 & 6 & 32 & 7 & 91 \\
\hline \multicolumn{8}{|c|}{ Number of females with breeding status recorded used to derive $\%$ of females breeding } \\
\hline 2000 & & & & & & 18 & 18 \\
\hline 2001 & & & & & & 20 & 20 \\
\hline 2002 & & & & & 5 & 8 & 13 \\
\hline 2003 & & & & & 4 & 4 & 8 \\
\hline 2004 & & & & & 2 & 2 & 4 \\
\hline 2005 & 15 & & & & 27 & 0 & 42 \\
\hline 2006 & 67 & & & & 34 & 0 & 101 \\
\hline 2007 & 77 & & & & 40 & 0 & 117 \\
\hline 2008 & 136 & & & & 48 & 0 & 184 \\
\hline 2009 & 43 & & & & 40 & 3 & 86 \\
\hline 2010 & 13 & 22 & 3 & 38 & & & \\
\hline \multicolumn{8}{|c|}{ Number of measurements used to derive mean adult body mass } \\
\hline 1998 & & 55 & 42 & 120 & & & 217 \\
\hline 1999 & & 125 & 85 & 99 & & & 309 \\
\hline 2000 & & 105 & 96 & 87 & & 64 & 352 \\
\hline 2001 & & 109 & 88 & 99 & 15 & 63 & 374 \\
\hline 2002 & & 107 & 95 & & 15 & 29 & 246 \\
\hline 2003 & & 54 & 87 & 100 & 16 & 21 & 278 \\
\hline 2004 & & 33 & 61 & & 13 & 12 & 119 \\
\hline 2005 & 43 & 14 & 8 & 72 & 74 & 1 & 212 \\
\hline 2006 & 163 & 8 & 3 & 14 & 80 & 0 & 268 \\
\hline 2007 & 181 & 3 & 6 & 7 & 100 & 1 & 298 \\
\hline 2008 & 382 & 5 & 6 & & 96 & 2 & 491 \\
\hline 2009 & 127 & 7 & 3 & 2 & 93 & 8 & 240 \\
\hline 2010 & 36 & 17 & 2 & 6 & 47 & 7 & 115 \\
\hline
\end{tabular}

means for demographic attributes were related to year since the start of the decline (Fig. 7).

The overall mean male : female ratio was $1.6(\mathrm{n}=2,882$, annual range $1.3-1.8$ ). There were no notable differences in sex ratio between sites, except for Camelar. This site had a high male bias $(\mathrm{M}: \mathrm{F}$ ratio $=1.9-2.7)$ prior to the local woylie decline, and this increased in the second and third years of the decline $(\mathrm{M}: \mathrm{F}=4.5, \mathrm{n}=22$ individuals in 2003 and $\mathrm{M}: \mathrm{F}=5.0, \mathrm{n}=12$ individuals in 2004; this site accounts entirely for the trend in increased male bias in these years in Fig. 7). Sample sizes at Camelar were smaller in 2005-2008 ( $0-2$ individuals) but the sex ratios were within the normal range in 2009 and $2010(\mathrm{M}: \mathrm{F}$ ratio $=1.7$, $\mathrm{n}=8$, and $\mathrm{M}: \mathrm{F}$ ratio $=1.3, \mathrm{n}=7$, respectively).

Overall, $97 \%$ of captured adult female woylies showed evidence of breeding (annual range 92-100\%, $\mathrm{n}=954$, where breeding status was reliably recorded across six sites). All females were breeding except in years $-1,0$ and 1 since the start of the decline, when $98 \pm$ SE $1.5 \%, 95 \pm$ SE $0.4 \%$ and $90 \pm$ SE 2.4\%, respectively, were breeding (Fig. 7).

Adult body mass was $900-1,800 \mathrm{~g}$ for males and 800-1,800 $\mathrm{g}$ for females (not including the body mass of pouch young). The annual mean body mass of adult woylies across the Upper Warren (1998-2010) was not significantly 


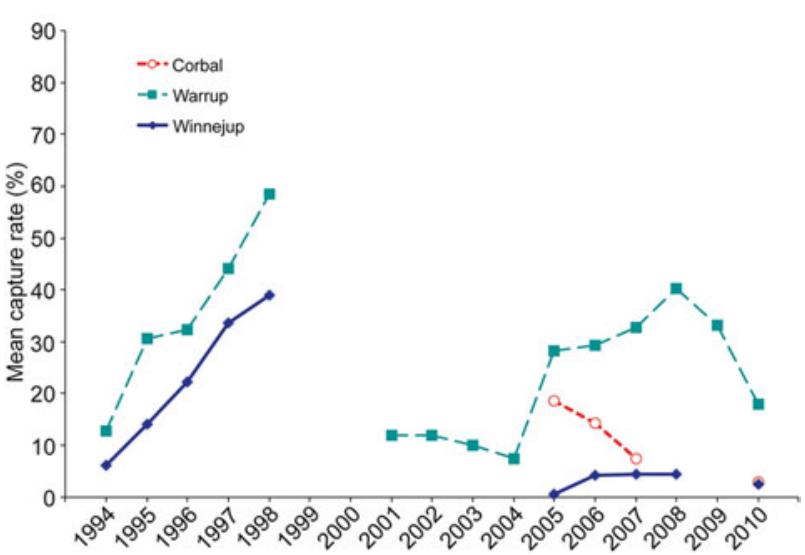

FIG. 2 Annual mean trap capture rates of woylies along monitoring transects in Greater Kingston (western Upper Warren) during 1994-2010.

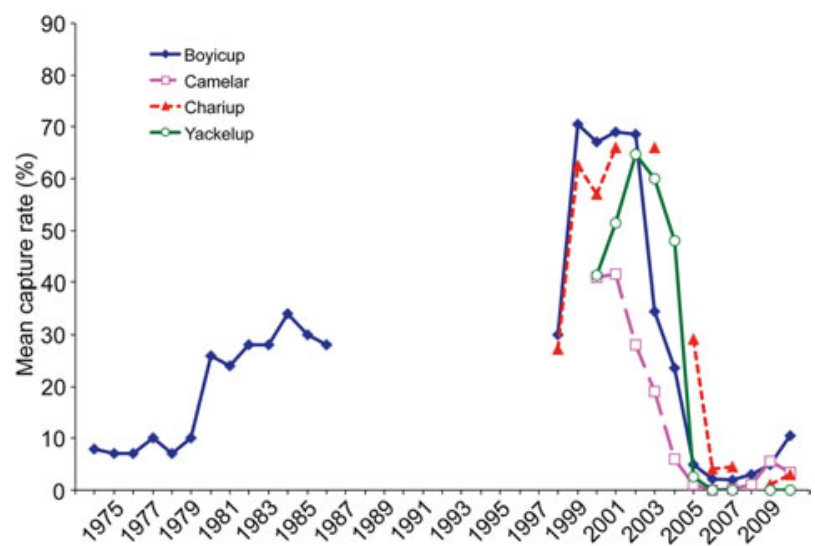

FIG. 3 Annual mean trap capture rates of woylies along monitoring transects in southern Perup (south-eastern Upper Warren) during 1974-2010.

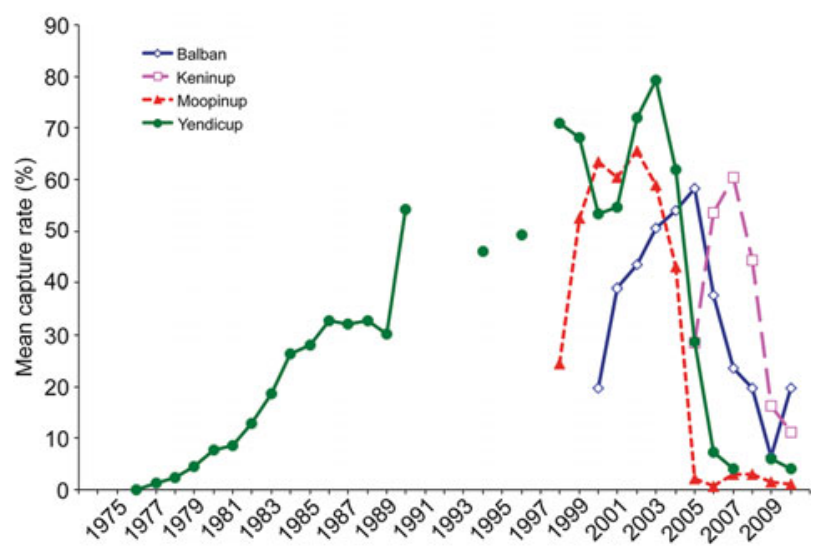

FIG. 4 Annual mean trap capture rates of woylies along monitoring transects in northern Perup (north-eastern Upper Warren) during 1976-2010.

different between sexes $(\mathrm{P}=0.23)$ or sites $(\mathrm{P}=0.32)$ or the interaction term for these two factors $(\mathrm{P}=0.37$; two-factor ANOVA, $n=114$ ). Mean body mass at sites increased in the 5 years following the commencement of decline, but some of

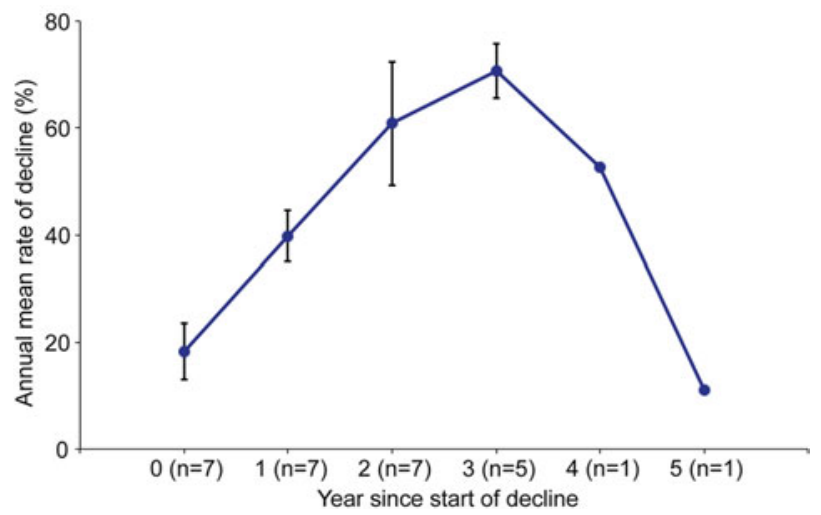

Fig. 5 Mean rate of decline in woylie trap capture rates in Perup, based on the number of years since the start of the decline.

these gains were lost again in the 8 th and 9 th years after the decline commenced (Fig. 7). The weight loss corresponded with an increasing trend in the mean woylie capture rate (particularly as a result of the increases at Warrup) that began 7 years after the decline began.

\section{Discussion}

The nature of the woylie decline and the approach to understanding it is pertinent to global efforts in species conservation. The unexpectedness, magnitude and speed of the decline are particularly salient and highlight the importance of adequate monitoring even when populations are abundant and not considered at risk (Groom, 2010).

The woylie decline is relevant to other co-occurring species that are threatened and/or declining, such as the numbat Myrmecobius fasciatus, wambenger Phascogale tapoatafa, ngwayir Pseudocheirus occidentalis, quenda Isoodon obesulus fusciventer, and chuditch Dasyurus geoffroii. Factors causing woylie decline may also affect these species, which are generally more difficult to investigate because of their more cryptic nature, lower abundances, and the limited data available. Therefore, resolving the causes of decline in the woylie may assist in the identification of the agents of decline in co-occurring species and vice versa.

Using a declining population diagnosis framework and characterizing the nature of the decline can help to identify its causes, which is necessary for effective management of the conservation and recovery of populations. The findings from the Upper Warren are also critical in determining whether the same factors are responsible for the concurrent declines in most of the other large woylie populations across southern Australia (Groom, 2010; Yeatman \& Groom, 2012).

\section{Characteristics of the decline}

There was a net loss of $95 \%$, or c. 160,000 woylies, during 2002-2010 in the Upper Warren (Wayne et al., 2013), and 


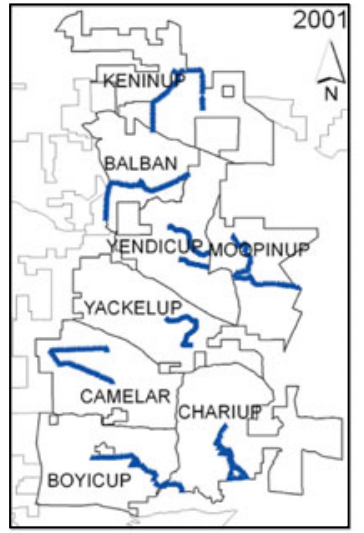

\section{Annual decline}
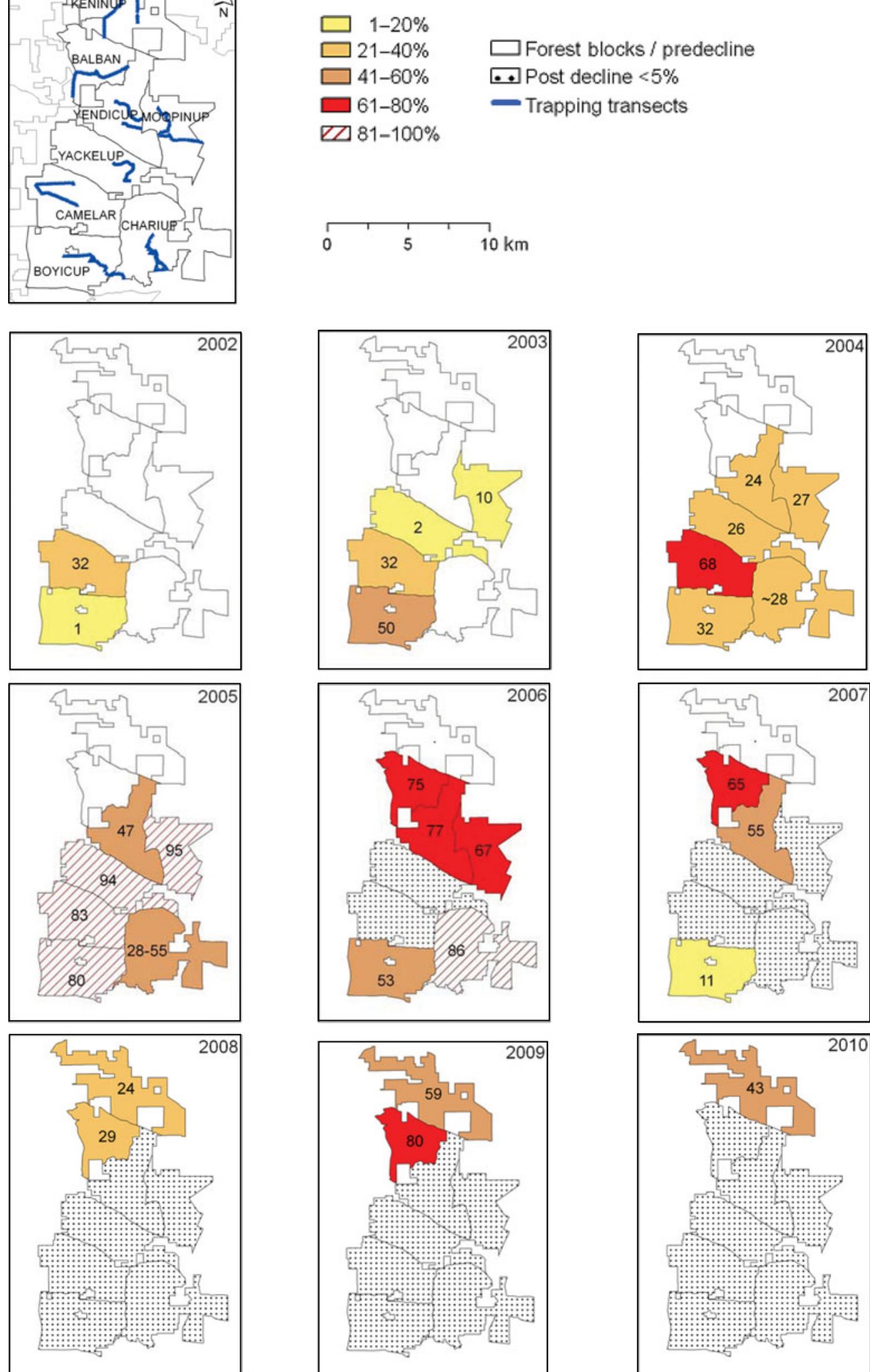

FIG. 6 Schematic spatial model of the annual rates of woylie decline in Perup, Upper Warren. Annual rates of decline are calculated based on changes in the mean annual capture rate and do not indicate the first detection of declines in any given area. Names and boundaries of forest blocks, and the locations of transects, are shown on the 2001 model. The numbers represent the decline (\%) in woylie trap capture rates. 


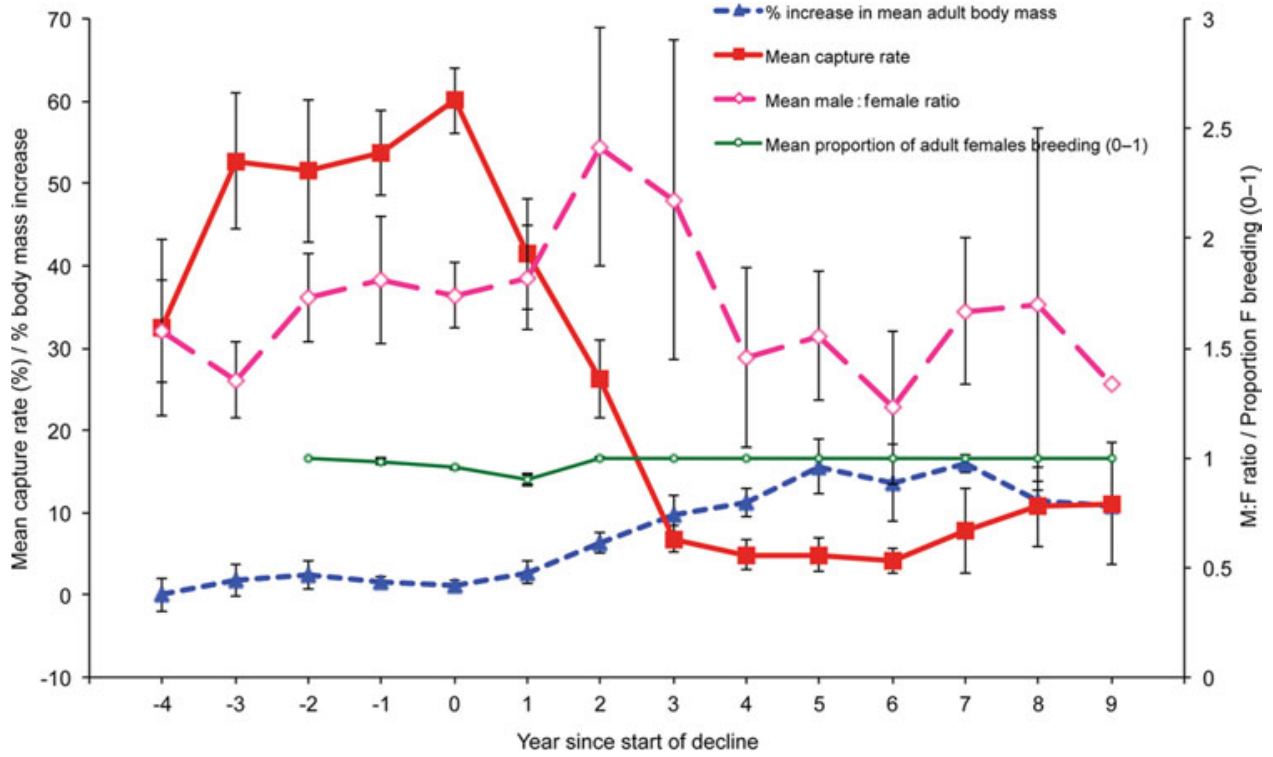

FIG. 7 Woylie demographic attributes in relation to year since the start of decline for sites in the Upper Warren region. the decline clearly shows a spatio-temporal pattern. Although the timing may have varied, many of the characteristics of decline were similar across the monitoring sites. The duration, successive annual rates of decline and magnitude of decline were also similar. Warrup is the only site to have undergone a substantial recovery but, having reached an apparent minimum threshold density common to all sites that have recently declined ( $>1.0$ woylie per ha), the population is declining again. Changes in some demographic attributes were apparently associated with decline, including a $15 \%$ increase in body mass in the 5 years following the commencement of the decline, up to $10 \%$ reduction in the proportion of adult females breeding, and at the Camelar site, a marked increase in the male bias 2-3 years into the decline. These findings provide potential clues to the cause and effect of the decline, but associations may be coincidental.

The generally high proportion of adult females breeding (overall mean of 97\%) is consistent with earlier findings (e.g. Christensen, 1980). The adult male bias in the Upper Warren (overall mean $\mathrm{M}: \mathrm{F}=1.6$ ) is in contrast to the female-dominated trapping results from the dense and stable woylie population within the fenced, 275 ha, predatorfree Karakamia Wildlife Sanctuary, Western Australia $(\mathrm{M}: \mathrm{F}$ ratio $=0.7 ; \mathrm{DEC}, 2008)$. Although there may be a real difference between populations, caution is advised when comparing areas with different animal densities and/or different trapping methods (including spatial arrangement and density of traps), given that the actual sex ratio of a population cannot be inferred directly from raw trapping data (Wayne et al., 2008b).

Female woylies had body mass of up to $1,800 \mathrm{~g}$, which is larger than past records (Christensen, 1995; de Tores \& Start, 2008). The post-decline increase in woylie body mass is most likely attributable to increased availability of food resources as a result of lower woylie density. Evidence of the species' responsiveness to food resources was found in the population at Karakamia, where body mass decreased by c. $10 \%$ to a mean of $1,070 \mathrm{~g}$ (and breeding became seasonal) when woylie numbers stabilized at an apparent carrying capacity after their introduction (in 1994) and initial population growth (DEC, 2008).

Mortality can be deduced as a driver of the decline, given that the rates of decline $(25-95 \%$ per annum at any given site) are greater than would be expected in the event of a complete failure of recruitment by reproduction and given an average life expectancy of 2.6-2.9 years (A. Wayne, unpubl. data) and 4-6 years (Christensen, 1995). There is no evidence of substantial emigration, based on trapping histories and radio-telemetry (A. Wayne, unpubl. data).

\section{Other woylie population declines}

Commonalities exist across other woylie populations that have recently declined. All of the major declines detected to date (DEC, unpubl. data) began within a 10-year period, although there is no apparent large-scale spatial pattern to the timing between populations (Fig. 8). Affected populations have typically declined by $90-100 \%$ and declines have occurred across much of the species' current range. Seven of the 10 populations with $>200$ individuals in 2001 have declined (Groom, 2010). All recorded declines have been on mainland Australia, where introduced foxes and cats were present. The substantial populations that have not declined are physically isolated by fences (Karakamia, Western Australia) or ocean (St Peter's and Wedge Islands, South Australia) in areas free of introduced predators. Further work is needed to distinguish the characteristics of populations that have and have not declined and to investigate the causes of decline. 


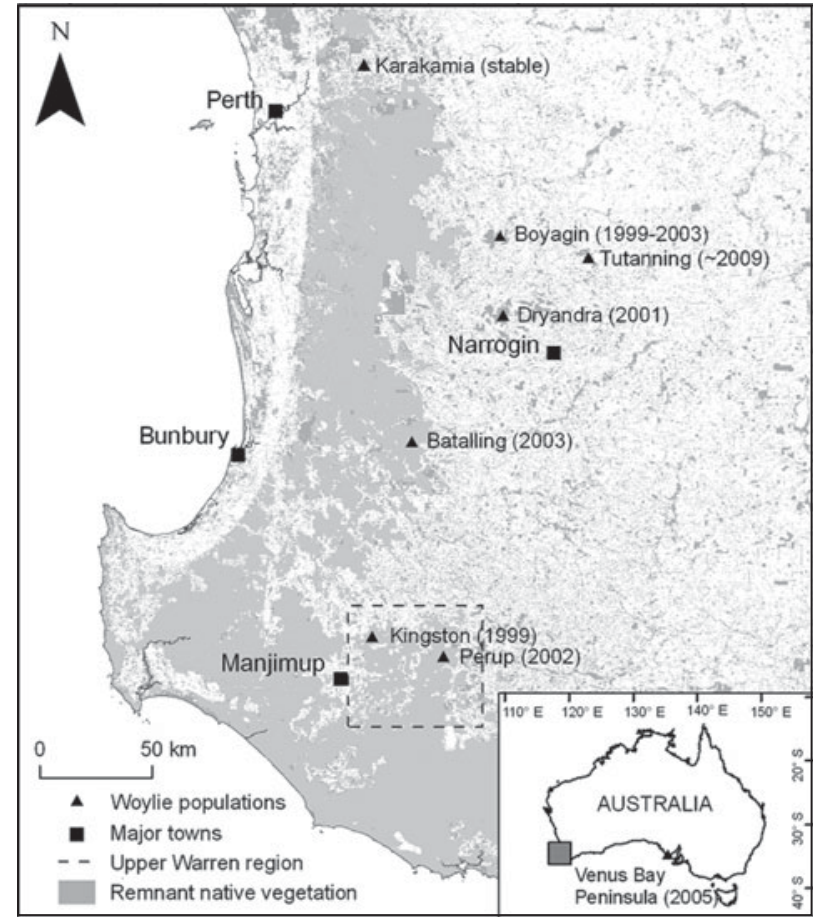

FIG. 8 Locations of woylie populations, with the year they began to decline shown in parentheses if applicable. The rectangle on the inset shows the location of the main map.

\section{Potential causes of decline}

Introduced predators (fox and cat), habitat loss and disease are among the principal factors thought to be responsible for historical declines of the woylie and other species in Western Australia (Burbidge \& McKenzie, 1989; Start et al., 1995; Short et al., 2005; Abbott, 2006, 2008). How these or other factors may relate to the current decline is not fully understood. Most potential agents of decline can be broadly categorized into four major groups: resources, predators, disease, and direct human interference.

Key resources include food, water, shelter, space and mates. Although food would appear to be the most likely of these to be a factor in woylie decline, available evidence indicates that food is unlikely to be a primary cause of decline in the Upper Warren: there was a marked increase in body mass after the commencement of a decline, and comparative spatio-temporal investigations of diet and the availability of sequestrate fungi (the woylie's primary food source) found no associations in relation to the recent decline (Zosky, 2012). The woylie does not require free water for survival (de Tores \& Start, 2008). Shelter and space are unlikely to be primary factors, given that there has been no major change in the habitat or its extent, nor has there been any indication of a major increase in competitors in the region (e.g. quenda and koomal Trichosurus vulpecula hypoleucus; Orell, 2004; DEC, unpubl. data). Mates should have been readily available, given the high densities of woylies prior to decline.
Human activities might have directly interfered with woylie breeding and/or survival. Perverse effects on trapped individuals include disrupted breeding success, reduced condition, injuries, increased stress and susceptibility to other mortality factors. These are unlikely causes of the decline, based on preliminary investigations (DEC, 2008) regarding the nature, timing and extent of activities and the characteristics of the decline. Habitat loss and modification, fire, and timber harvesting are also not readily associated with the decline in the Upper Warren (DEC, 2008).

Based on the available evidence collated to date, the leading hypothesis is that woylies have been made more vulnerable to predation by disease, with mortality being the primary driver of decline. Feral cats Felis catus, and to a lesser extent foxes, have been associated with most woylie mortalities observed during the woylie declines in the Upper Warren (DEC, 2008; A. Wayne, unpubl. data) and Dryandra (N. Marlow pers. comm.). However, the characteristics of the decline in the Upper Warren are not readily explained by predation alone, and the clear spatio-temporal pattern of its progression through the region is consistent with an agent with limited mobility, such as some infectious diseases, moving through the population. A high prevalence of moderate to severe skin and fur conditions has been associated with populations undergoing decline (DEC, 2008; A. Wayne, unpubl. data), as have haematological attributes such as lymphocytosis (Pacioni, 2010; Pacioni et al., 2013) and some parasites (DEC, 2008; Smith et al., 2008), although the significance of these associations is unknown. The apparent association of woylie density and proportion of breeding females with the commencement of initial and secondary declines at sites within the Upper Warren ( $>_{1}$ woylies per ha) is also consistent with some diseases and resources (otherwise dismissed as a putative cause in this case) and merits further investigation.

Disease has been shown to be a key factor in population declines in other species (Tompkins et al., 2003; Miller et al., 2004; Pedersen \& Greives, 2008; McCallum et al., 2009; Foley et al., 2011), and in some cases extinction (Skerratt et al., 2007; Wyatt et al., 2008; Smith et al., 2009). Diseases may be genetic, viral, parasitic, bacterial, nutritional or toxicological. Several organisms hosted by the woylie have been identified recently (Smith et al., 2008; Bennett et al., 2010; Parameswaran et al., 2010; Kaewmongkol et al., 2011; Botero et al., 2013; Thompson et al., 2013), but whether they are related to the decline, and, if so, their significance, remains to be verified. In the meantime, activities involving woylie populations must strictly adhere to disease risk management protocols (Chapman et al., 2011).

\section{Decline diagnosis development}

This and an earlier study (Wayne et al., 2013) have addressed the first four steps of the woylie decline diagnosis framework 
for the Upper Warren populations. The next steps are to continue to use evidence to shortlist the potential agents of decline, test the strength and nature of observed associations, and seek direct evidence of the actual causes. The hypothetico-deductive approach (Caughley, 1994) used in this study involves parallel lines of enquiry addressing the numerous possible agents of decline and factors such as climate change and fire. A population or site comparison approach may also assist in identifying associations between woylie demographics, survival and mortality, predators, disease, and resources. Specific targeted investigations are also necessary. Given the diversity and complexity involved in investigating the causes of decline, a corresponding diversity of multi-disciplinary collaboration is needed.

\section{Species decline in perspective}

The recent and rapid 90\% decline of the woylie is particularly challenging for the conservation of the species, given that all indigenous populations have declined. These encapsulated the extant genetic diversity of the species, which prior to the recent decline had lost c. 50\% of its genetic diversity and $98 \%$ of its abundance over the 200 years since the settlement of Australia by Europeans (Hunt, 2010). Nonetheless, the genetic diversity in these populations had generally remained high prior to recent declines (Pacioni et al., 2011).

The small size of remnant populations, and the uncertainty as to whether these populations will be able to recover naturally, increases the risk of continued genetic loss and local extinction, which has already occurred at Tutanning (Pacioni et al., 2011; DEC, unpubl. data). Other particularly vulnerable populations include the remaining indigenous populations (Dryandra, Upper Warren) and the population at Batalling. Since 2001 the Dryandra population has undergone $>90 \%$ decline. The Batalling population, previously the largest translocated population in Western Australia (<10,000 individuals; Wayne et al., 2013), has undergone $99 \%$ decline and has remained at extremely low levels since 2007 (Yeatman \& Groom, 2012).

Insurance populations that adequately secure the remaining genetic diversity of the species are also necessary to maximize the short- and long-term conservation and recovery prospects of the species. This is being addressed, in part, by the establishment of the Perup Sanctuary ( 420 ha predator-free enclosure of native habitat in Perup Nature Reserve) in 2010 to complement Karakamia Wildlife Sanctuary.

\section{Conclusions}

The often spectacular recovery of woylie populations in response to fox control (Orell, 2004) demonstrates the resilience of the species. However, while the recent decline continues, residual populations remain low and no recoveries are sustained, the conservation risks increase. Diagnosing the decline remains the most effective way to improve the long-term conservation prospects for the species but it is also important to understand the factors limiting recovery (small population paradigm; Caughley, 1994).

A systematic comparative assessment of the associative evidence from other woylie populations is key to the diagnosis of the decline and impediments to recovery. A particular focus on disease and predators is recommended. However, direct evidence will ultimately be necessary to unequivocally confirm the causes of the decline and factors limiting population recovery.

Given the rapidity and magnitude of the woylie decline, active adaptive management (Walters \& Holling, 1990; Lee, 1999) within a rigorous scientific framework may be a timely and effective means of providing direct evidence regarding key putative agents, such as introduced predators, while also aiming to deliver better conservation outcomes. Adequate and standardized ecological monitoring (Yoccoz et al., 2001; Legg \& Nagy, 2006) may prove equally important in gathering associative evidence of the most likely putative agents of decline. Effective monitoring is also critical to the timely detection of significant population changes. These priorities are consistent with the national recovery plan (Yeatman \& Groom, 2012) and should form the basis of an integrated and comprehensive conservation and management strategy for the species, with adequate resources and support to deliver a favourable conservation outcome for this keystone species and potentially for other threatened species.

\section{Acknowledgements}

Many professionals, organizations, students and volunteers have been actively involved with the Woylie Conservation Research Project, of which this study is a component. Access to historical datasets was provided by various custodians: P. Christensen, N. Burrows, G. Liddelow, B. Ward, P. Orell and DEC. Funding sources included the Western Australia Department of Environment and Conservation (now the Department of Parks and Wildlife), the Western Australian Government, the Australian Research Council and the Environment Division of the United Nations Association of Australia (WA) Incorporated. Cassidy Newland produced Fig. 1. Ian Abbott, Carlo Pacioni, Joern Fischer and two anonymous reviewers provided helpful comments.

\section{References}

Аввотт, I. (2006) Mammalian faunal collapse in Western Australia, 1875-1925: the hypothesised role of epizootic disease and a 
conceptual model of its origin, introduction, transmission, and spread. Australian Zoologist, 33, 530-561.

Аввотт, I. (2008) Historical perspectives of the ecology of some conspicuous vertebrate species in south-west Western Australia. Conservation Science Western Australia, 6, 1-214.

Bennett, M.D., Reiss, A., Stevens, H., Heylen, E., Van Ranst, M., Wayne, A.F. et al. (2010) Genomic characterization of a novel marsupial papillomavirus: Bettongia penicillata papillomavirus type 1. Journal of Virology, 84, 5448-5453.

Botero, A., Thompson, C.K., Peacock, C.S., Clode, P.L., Nicholls, P.K., Wayne, A.F., Lymbery, A.J. \& Thompson, R.C.A. (2013) Trypanosomes genetic diversity, polyparasitism and the population decline of the Critically Endangered Australian marsupial, the brush tailed bettong or woylie (Bettongia penicillata). International Journal for Parasitology: Parasites and Wildlife, 2, 77-89.

Burbidge, A.A. \& McKenzie, N.L. (1989) Patterns in the modern decline of Western Australia's vertebrate fauna: causes and conservation implications. Biological Conservation, 50, 143-198.

Burrows, N.D. \& Christensen, P.E.S. (2002) Long-term trends in native mammal capture rates in a jarrah forest in south-western Australia. Australian Forestry, 65, 211-219.

Caughley, G. (1994) Directions in conservation biology. Journal of Animal Ecology, 63, 215-244.

Caughley, G.C. \& Gunn, A. (1996) Conservation Biology in Theory and Practice. Blackwell Science, Cambridge, USA.

Chapman, T., Sims, C. \& Mawson, P. (2011) Minimising Disease Risk in Wildlife Management, 3rd edition. Department of Environment and Conservation, Perth, Australia.

Christensen, P. (1995) Brush-tailed Bettong Bettongia penicillata. In The Australian Museum Complete Book of Australian Mammals (ed. R. Strahan), pp. 292-293. Reed Books, Chatswood, Australia.

Christensen, P.E.S. (1980) The biology of Bettongia penicillata Gray 1837, and Macropus eugenii Desmarest 1817, in relation to fire. Bulletin 91. Western Australia Forests Department, Perth, Australia.

DeC (Department of Environment and Conservation) (2008) Diagnosis of recent woylie (Bettongia penicillata ogilbyi) declines in southwestern Australia. In Progress Report of the Woylie Conservation Research Project (ed. A.F. Wayne), pp. 1-314. Department of Environment and Conservation, Perth, Australia.

DeC (Department of Environment and Conservation) (2012) Perup Management Plan 2012. Department of Environment and Conservation, Perth, Australia.

De Tores, P. \& Start, A.N. (2008) Woylie, Bettongia penicillata. In The Mammals of Australia, 3rd edition (eds S. Van Dyck \& R. Strahan), pp. 291-292. Reed New Holland, Sydney, Australia.

Foley, J., Clifford, D., Castle, K., Cryan, P. \& Ostefeld, R.S. (2011) Investigating and managing the rapid emergence of white-nose syndrome, a novel, fatal, infectious disease of hibernating bats. Conservation Biology, 25, 223-231.

Garkaklis, M., Bradley, S.J. \& Wooler, R.D. (2004) Digging and soil turnover by a mycophagous marsupial. Journal of Arid Environments, 56, 569-578.

Groom, C. (2010) Justification for continued conservation efforts following the delisting of a threatened species: a case study of the woylie, Bettongia penicillata ogilbyi (Marsupialia: Potoroidae). Wildife Research, 37, 183-193.

Hunt, H. (2010) Molecular evidence of a genetic bottleneck using temporal genetic data in an endangered marsupial, Bettongia penicillata ogilbyi. BSc thesis. Murdoch University, Murdoch, Australia.
Kaewmongkol, G., Kaewmongkol, S., Burmej, H., Bennett, M.D., Fleming, P., Adams, P.J. et al. (2011) Diversity of Bartonella species detected in arthropod vectors from animals in Australia. Comparative Immunology, Microbiology and Infectious Diseases, 34, 411-417.

LEE, K.N. (1999) Appraising adaptive management. Conservation Ecology, 3, 3.

LEGG, C.J. \& NAGY, L. (2006) Why most conservation monitoring is, but need not be, a waste of time. Journal of Environmental Management, 78, 194-199.

McCallum, H., Jones, M., Hawkins, C., Hamede, R., Lachish, S., SinN, D.L. et al. (2009) Transmission dynamics of Tasmanian devil facial tumor disease may lead to disease-induced extinction. Ecology, 90, 3379-3392.

McCaw, L., Hamilton, T. \& Rumley, C. (2005) Application of fire history records to contemporary management issues in south-west Australian forests. In 6th National Conference of the Australian Forest History Society Inc (eds M.C. Calver, H. Bigler-Cole, G. Bolton, J. Dargavel, A. Gaynor, P. Horwitz et al.), pp. 555-564. Millpress Science Publishers, Rotterdam, Netherlands.

Miller, M.A., Grigg, M.E., Kreuder, C., James, E.R., Melli, A.C., Crosbie, P.R. et al. (2004) An unusual genotype of Toxoplasma gondii is common in California sea otters (Enhydra lutris nereis) and is a cause of mortality. International Journal of Parasitology, 34, 275-284.

Orell, P. (2004) Fauna monitoring and staff training: Western Shield review-February 2003. Conservation Science Western Australia, 5, 51-95.

Pacioni, C. (2010) The population and epidemiological dynamics associated with recent decline of woylies (Bettongia penicillata) in Australia. PhD thesis. Murdoch University, Murdoch, Australia.

Pacioni, C., Wayne, A.F. \& Spencer, P. (2011) Effects of habitat fragmentation on population structure and long distance gene flow in an endangered marsupial: the woylie. Journal of Zoology, 283, 98-107.

Pacioni, C., Robertson, I., Maxwell, M., Van Weenan, J., WAyne, A.F. (2013) Hematologic characteristics of the woylie (Bettongia penicillata ogilbyi). Journal of Wildlife Diseases, 49, 816-830.

Parameswaran, N., Thompson, A., Sundar, N., Pan, S. \& Grigg, M. (2010) Nonarchetypal Type II-like and atypical strains of Toxoplasma gondii infecting marsupials of Australia. International Journal for Parasitology, 40, 635-640.

Pedersen, A.B. \& Greives, T.J. (2008) The interaction of parasites and resources cause crashes in a wild mouse population. Journal of Animal Ecology, 77, 370-377.

Peery, M.Z., Beissinger, S.R., Newman, S.H., Burkett, E.B. \& Williams, T.D. (2004) Applying the declining population paradigm: diagnosing causes of poor reproduction in the marbled murrelet. Conservation Biology, 18, 1088-1098.

Short, J., Atrins, L. \& Turner, B. (2005) Diagnosis of Mammal Declines in Western Australia, with Particular Emphasis on the Possible Role of Feral Cats and Poison Peas. CSIRO Sustainable Ecosystems, Perth, Australia.

Skerratt, K.F., Berger, L., Speare, R., Cashins, S., McDonald, K.R., Phillott, A.D. et al. (2007) Spread of chytridiomycosis has caused the rapid global decline and extinction of frogs. EcoHealth, 4, 125-134.

Smith, A., Clark, P., Averis, S., Lymbery, A.J., Wayne, A.F., Morris, K.D. \& Thompson, R.C.A. (2008) Trypanosomes in a declining species of threatened Australian marsupial, the brush-tailed bettong Bettongia penicillata (Marsupalia: Potoroidae). Parasitology, 135, 1-7. 
Smith, K.F., Acevedo-Whitehouse, K. \& Pederson, A.B. (2009) The role of infectious diseases in biological conservation. Animal Conservation, 12, 1-12.

Start, A.N., Burbidge, A.A. \& Armstrong, D. (1995) Woylie Recovery Plan. Wildlife Management Program No.16. Western Australian Department of Conservation and Land Management and South Australian Department of Environment and Natural Resources, Perth, Australia.

Thompson, C.K., Botero, A., Wayne, A.F., Godfrey, S.S., Lymbery, A.J. \& Thompson, R.C.A. (2013) Morphological polymorphism of Trypanosoma copemani and description of the genetically diverse $T$. vegrandis sp. nov. from the Critically Endangered Australian potoroid, the brush-tailed bettong (Bettongia penicillata (Gray, 1837)). Parasites \& Vectors, 6, 121-133.

Tompkins, D.M., White, A.R. \& Boots, M. (2003) Ecological replacement of native red squirrels by invasive greys driven by disease. Ecology Letters, 6, 189-196.

Walters, C.J. \& Holling, C.S. (1990) Large-scale management experiments and learning by doing. Ecology, 71, 2060-2068.

Wayne, A.F., Cowling, A., Lindenmayer, D.B., Ward, C.G., Vellios, C.V., Donnelly, C.F. \& Calver, M.C. (2006) The abundance of a threatened arboreal marsupial in relation to anthropogenic disturbances at local and landscape scales in Mediterranean-type forests in south-western Australia. Biological Conservation, 127, 463-476.

Wayne, A.F., Cowling, A., Rooney, J.F., Ward, C.G., Wheeler, I.B., Lindenmayer, D.B. \& Donnelly, C.F. (2005) Factors affecting the detection of possums by spotlighting in Western Australia. Wildlife Research, 32, 689-700.

Wayne, A.F., Friend, T., Burbidge, A., Morris, K. \& van Weenen, J. (2008a) Bettongia penicillata. In IUCN Red List of Threatened Species v. 2009.2. Http://www.iucnredlist.org [accessed October 2012].

Wayne, A.F., Maxwell, M., Ward, C., Vellios, C., Ward, B., Liddelow, G.L. et al. (2013) Importance of getting the numbers right: quantifying the rapid and substantial decline of an abundant marsupial, Bettongia penicillata. Wildlife Research, 40, 169-183.

Wayne, A.F., Rooney, J., Morris, K.D. \& Johnson, B. (2008b) Improved bait and trapping techniques for chuditch (Dasyurus geoffroii): overcoming reduced trap availability due to increased densities of other native fauna. Conservation Science Western Australia, 7, 49-56.

Wyatt, K.B., Campos, P.F., Gilbert, M.T.P., Kolokotronis, S.-O., Hynes, W.H., DeSalle, R. et al. (2008) Historical mammal extinction on Christmas Island (Indian Ocean) correlates with introduced infectious disease. PLOS ONE, 3, e3602.

Yeatman, G.J. \& Groom, C.J. (2012) National Recovery Plan for the Woylie Bettongia Penicillata. Wildlife Management Program No. 51. Department of Environment and Conservation, Perth, Australia.

Yoccoz, N.G., Nichols, J.D. \& Boulinier, T. (2001) Monitoring biological diversity in space and time. Trends in Ecology \& Evolution, 16, 446-453.

Zоsку, K. (2012) Food resources and the decline of woylies Bettongia penicillata ogilbyi in southwestern Australia. PhD thesis. Murdoch University, Murdoch, Australia.

\section{Biographical sketches}

Adrian Wayne, Marika Maxwell, Colin Ward and Chris Vellios are a research team focusing on the conservation and management of threatened and sensitive species, with an interest in the ecology of forest vertebrate fauna in south-west Australia. IAN WILSON and JULIA WAYNE are responsible for the management of biodiversity and conservation values on public lands, including the region where this study was focused. MatTheW Williams is a biometrician. 